\title{
WASTE NOT, WANT NOT. WHAT ARE THE DRIVERS OF SUSTAINABLE MEDICINES RECYCLING IN NATIONAL HEALTH SERVICE (NHS) HOSPITAL PHARMACIES (UK)?
}

\begin{abstract}
Medicines management is only one part of NHS (UK) procurement and management, but essentially a very expensive part. In December 2012 the Department of Health issued an action plan to improve the use of medicines and reduce waste. There is an onus therefore on the NHS to ensure that they are as efficient in the medicines management as possible in all aspects of the supply chain in order to ensure sustainability (economically and operationally). To do this consideration must be given to medicines optimization, from procurement, through to storage, dispensing, compliance and finally waste prevention and reduction and waste retrieval. As part of the larger National Health Service (UK), hospital pharmacy places strong emphasis on contributing to the efficiency targets through reductions in waste and drug spending, and best practice. The purpose of this study is to examine medicines reverse logistics practice within the NHS hospital pharmacies, and the operational strategy which drives such practices. The overarching aim is to explore through qualitative analysis the variance and commonality in strategy and practice in what is a standard logistical activity. The outputs offer transparency of medicines RL as practiced by NHS professionals and contribute to ongoing discussions within the Department of Health (NHS UK) on best practice governing waste medicines recycling processes.
\end{abstract}

A qualitative approach was adopted in undertaking this research study, utilizing a purposive study sample. The survey examined practice in 45 hospitals as individual cases across all stages in the medicines reverse logistics system. The findings indicated there is some commonality in the strategy employed in conducting medicines recycling, and all 3 drivers are prevalent in undertaking recycling and encouraging a more sustainable approach, i.e., economic, corporate citizenship, and legislation. However, the means by which the same objective was achieved differed, such as resource utilisation, training etc.

\section{Introduction}

In this era of austerity, every penny is accounted for and none more so than the healthcare systems and services across the world. In the NHS (UK) initiatives have been launched to prepare its services for this period of efficiencies and savings. Such initiatives include QIPP (Quality, Innovation, Productivity and Prevention). "The quality, innovation, productivity and prevention (QIPP) challenge is our opportunity to prepare the NHS to defend and promote high quality care in a tighter economic climate. .... the NHS needs to be making efficiency savings of £15-£20 billion per year by 2013/14". (Department of Health, 2010). As the NHS (UK) is publicly accountable then vigilance is paid to what is spent and how it is spent: "Today £1 of every $£ 13$ (7.7\% GDP) produced by the UK economy is spent on healthcare - a level that matches most other European countries. Making sure that this investment is used as effectively as possible is a key responsibility for us all (Department of Health, 2010).

Medicines management is only one part of NHS (UK) procurement and management, but essentially a very expensive part. According to the Commercial Medicines Unit (Department of Health, 2013), NHS hospitals in England currently spend around £3.6 billion annually on pharmaceuticals. This has risen from £2.2. billion in 2005. There is an onus therefore on the NHS to ensure that they are as efficient in the medicines management as possible in all aspects of the supply chain in order to ensure sustainability (economically and operationally). To do this consideration must be given to medicines optimization; from procurement, through to storage, dispensing, compliance and finally waste prevention and reduction and waste retrieval.

In all sectors, the logistics of managing returned unused, unsold or damaged goods back into the upstream supply chain and associated activities of handling, consolidation and disposal such products is becoming of increasing interest in reducing costs and maximizing efficiencies (Cherrett et al., 2012). Within hospital pharmacy as part of the larger National Health Service (UK), there is a strong emphasis on contributing to the efficiency targets through reductions in waste and drug spending, as well as better practice (PharmaTimes Online, 2011a). The NHS Supply Chain asserts that they are committed to a sustainable future by meeting objectives of improving energy efficiencies, reducing emissions and pollutions, increasing recycling and reducing use of natural resources. The operations 
strategy within the NHS Supply Chain is the specific decisions and actions that play a key role in achieving these objectives, The construction of the operation strategy requires inputs from the four perspectives, including top down management (internal directives and external influences) bottom up activity (staff input), market requirements (the customers, patients, stakeholder influence) and operational resources (again staff) (Slack et al., 2010). Good sustainable practices will be the norm if there is a robust operational strategy and delivery mechanisms in place.

The aim of this study is to examine medicines recycling (as part of the wider reverse logistics $(R L)$ agenda) practice within the NHS Pharmaceutical Supply Chain (PSC) (UK), with a focus on hospital pharmacy, and the drivers which determine such practice. The areas examined included current recycling systems/practice, strategy, resource allocation, governance, and the use of technology in pharmacy recycling systems. Regional hospital pharmacy operational groups ( 5 in total who for the purpose of this paper will be known as Group A, B, C, D and E; 4 from mainland England and 1 outside of England) were approached and agreed to be involved in an online survey. The responses received represented $45 \mathrm{NHS}$ organisations.

The results indicate that there is commonality across all the hospitals as to why recycling activity is undertaken, the main reason provided that it is seen to be the right thing to do in order to be more efficient, save money and reduce waste. In doing so it saves money for the NHS and money for the individual hospitals and trusts. The weighting attached to the reasons however differed between regions. The outlying region was Group E (outside of mainland England). The driving reason for medicines recycling as determined by this group was opposite to all of the mainland regions. However, there were only 3 responses from Group E, so they cannot be considered as representative for the whole region. These participants felt that recycling was performed due to policy, hazard reduction and environmental (green) consciousness, as opposed to savings or waste reduction. The findings also indicated that there was a disparity in resources used to facilitate this process, for example, the quantity and grading of staff involved in recycling activity, and the types of process technology employed which includes pharmacy computer systems and robots.

According to the majority of respondents (82\%), medicines waste was disposed of by a third party and most of the recycling activity was steered by internal practice/protocols. External legislation/drivers which could influence this practice but does not play a key role came from sources such as; the Department of the Environment, Quality Control North West and the Pharmaceutical Society of Northern Ireland. $73 \%$ of participants felt that their practice was managed and steered more from in-house and local influences such as their own protocols and policies. Where guidance was sought and appreciated it was mainly from local sources such as Regional pharmacy groups and Regional pharmacy specialists as opposed to national or government sources (e.g. Department of Health). Only $50 \%$ of the study felt that external sources would have a positive impact on their recycling activity.

This study focuses on returned medicines waste analysis and processing and not waste disposal/incineration as part of a RL system. Any reference to waste management is as part of stock returns review and recycling as opposed to incineration, denaturating etc. The discussion below will comment on $R \mathrm{~L}$ and strategy before presenting the findings of this study, analysis and conclusions.

\section{Pharmaceutical Management in the NHS (UK)}

As identified in Figure 1 below the management of pharmaceuticals within the NHS (UK) is undertaken by numerous parties. The model indicates the extensive logistics operation behind pharmaceutical management and also the widening participation of all players (See Figure 1).

\section{Take in Figure 1}

Rees (2011) in his evaluation comments on the number of players but in despair at the 'disconnectedness' within the industry. He comments "the frantic search to discover blockbuster drugs has resulted in a disconnected industry which in turn is disconnected from its supply chains. This together with the continued belief that serendipity can form the basis of a sustainable business model, kills the will to change" (395: 2011). The industry is such that there has been 
an increase in new operators entering and providing products and services, e.g. offshoots of existing providers such as Evolution Homecare, a Celesio AG family company who also own AAH pharmaceuticals and Lloyds Pharmacy (AAH.co.uk, 2013).

There are a number of external associations who regulate or guide activity in the pharmaceutical supply chain, both in the NHS and in the pharmaceutical section e.g. manufacturers, wholesalers etc. Some include the Department of Health, Commercial Medicines Unit (within the Department of Health), Medicines and Healthcare products Regulatory Agency (MHRA) and the National Patient Safety Agency (NPSA) to mention a few. These parties all have a vested interest in the safe and effective management of medicines from sourcing to dispensing in the NHS (UK).

\section{Reverse Logistics in action - waste not, want not.}

Reverse Logistics $(\mathrm{RL})$ is defined as "the process of planning, implementing and controlling the efficient, cost-effective flow of raw materials, in process inventory, finished goods and related information from the point of consumption to the point of origin for the purpose of recapturing or creating value or for proper disposal" (Rogers and Tibben-Lembke, 1999, pp2). The main activities in a $R L$ system are reducing resources, reusing materials, recycling products, refurbishing, repair, remanufacturing, and disposing waste (Van Hoek, 1999). The benefits of $R L$ has been identified as decreased investment in resources (Andel, 1997), reduced material cost realised through the value reclamation in reuse, remanufacturing, repair, refurbishment, reconfiguration (South, 1998); and improved consumer satisfaction by offering warranty and returning service and building the consumer confidence in the company brand (Blumberg, 1999). Most of the RL literature in the past investigated how to improve business performance in industrial sectors such as; automobile (Lebreton and Tuma, 2006), electronic waste (Lau and Wang, 2009), computer (Shih, 2001), paper (Pati et al., 2008), packaging material (Gonzalez-Torre et al., 2004), bottling or glass (González-Torre and Adenso-Díaz, 2006) and batteries (Zhou et al., 2007).

Waste in general has gained ground and been the focus of much attention recently in not only healthcare provision but in relation to the circular economy; sustainability of resources e.g. metals such as tellurium and lithium (Marshall, 2011) and shale gas fracking (Mc Kenna, 2012); food waste generation and reduction) (Coghlan, 2013) and green technologies e.g. garbage sorting robots (Lovino, 2011). Researchers and practitioners advocate the advent of a circular economy advising operations to consider a 'cradle to cradle approach' as opposed to 'cradle to grave'. By this they ask us to focus on the design of the product for re-use after its normal life cycle as opposed to how it can be safely disposed. Waste therefore in this sense has a value in that it has the capacity to become a new product $-\mathrm{a}$ 'second life'. This is further supported by the Ellen McArthur Foundation (2010) who state that: "Cradle to cradle design means that we can eliminate the concept of waste. It doesn't support guilt language. It's not about reduction, avoidance or minimisation. It's about abundance" (McDonough and Braungart, 33:2002). However there is also the school of thought which purports that in undertaking recycling in certain supply chains "The end customer actually and voluntarily pays in both monetary terms and own work in order to help another actor further along the supply chain to exploit the value created" (Huge-Brodin and Anderson, 9:2008).

Waste medicines once returned by patients are destined for final disposal therefore they have no residual value. This contradicts the statement asserted by Huge-Brodin and Anderson (2008) above. The question must therefore be asked, what is the value of this product and hence why return it? The innate value attached to this product return is twofold: 1) it removes the product from circulation and from the domestic environment therefore reducing the risk of accidental injury or planned product abuse; 2) it provides valuable information which can be used to assess the efficiency and effectiveness of the prescribing and dispensing process (who the prescriber is, the nature of the product, how the medicines are dispensed, and the quantity dispensed). The cradle to cradle philosophy here doesn't fit. Medicines returned by patients cannot be reused and are disposed of. However some stock item medicines within hospital pharmacy, once retrieved from the internal supply chain e.g. wards prior to end of shelf life, can be returned to stock and redeployed for use prior to obsolescence. These products can have an economic value and a 'second chance of use' as opposed to a 'second life' via remanufacture for re-use (in the case of many products as espoused by circular economy theorists and the concept of circularity).

Research to date in this area has generally focused on the return of medical products from a clinical perspective (Braund et al., 2009; Mackridge and Marriott, 2007), and extensive amount research has been conducted by 
environmental scientists to investigate the environmental effects caused by the pharmaceutical waste (Daughton and Ternes, 1999), on medical waste management and disposal (Shareefdeen, 2012; Hassan et al., 2008; Jang et al., 2006) but there is very little research and practice on medication recycling from a RL or operational perspective (Xie and Breen, 2012; Qdais et al., 2007; Ritchie et al., 2000).

\section{Driving Strategy - To recycle or not?}

The operations strategy is defined as "the total pattern of decisions which shape the long-term capabilities of any type of operations and their contribution to the overall strategy, through the reconciliation of market requirements with operations resources" (Slack and Lewis, 3:2002). This being the case, an operation decides what it wants to do and how in alignment with its strategy.

Operational performance is measured by objectives known as cost, quality, speed, dependability and flexibility (Slack et al., 2010). Under pressure from government, consumers, investors, workforce and communities, organisations are requested to achieve sustainability as an additional operational objective. Therefore, integrating environmental management principles within the an overarching operational strategy becomes necessary, which means the organisation aims to appeal to green customer segments, by developing a green strategy in marketing, operations and financial areas. In this way, the organisational culture and interfunctional coordination will be developed to be more environmentally friendly. World class companies, such as AT\&T, BMW, etc., are incorporating the environmental management into their strategic planning as well as their daily operations not only to ensure their compliance with legal requirements but also are managed in a sustainable way (Gupta, 1995).

The operations strategy plays a critical role in developing management systems and making decision that affect financial performance, environmental performance (Gupta and Sharma, 1996), and public images. The operations strategy can set guides in adjusting the operation's various resources and processes to fall into line with it. Strategy can therefore provide internal and external guidance to all stakeholders. Operations will differ as to why they choose to adopt a strategy which supports sustainable development and nurtures green activities.

Kleiner (1991) advised that a company build the environmental management into the three fundamental operational areas, i.e., product planning, disclosure policy (how much open disclosure of pollution and health information should companies support), and pollution prevention programmes. Gupta (1995) provided an overview of environmental management from an operations perspective, and claimed that operations strategies, objectives and decisions must be reviewed continuously in the light of environmental opportunities. The environmental management must be built into all the operational functions, including product design, waste minimisation programmes, pollution prevention strategy, waste audit process, green technologies, and recycling system. Angell and Klassen (1999) generated a broad framework to integrate environmental issues to the operations strategy. The wider opportunities have been identified to improve operational practices, ranging from manufacturing strategy, quality, supply chain management, to technology management.

The three main drivers that motivate companies to adopt $R \mathrm{~L}$ are identified as: economic, corporate citizenship, and legislation (de Brito et al., 2004). Economic drivers indicate that $\mathrm{RL}$ activities such as reducing waste, reuse of materials, remanufacturing, recycling and product refurbishing have the potential to minimise economic cost and improve profitability. Corporate citizenship could also be interpreted as corporate social responsibility, and it defines the business's engagement in ethical issues from an ethical perspective that tries to bring greater good to society. From a supply chain management perspective, it means that companies who seek for sustainable development, efficiently and effectively handle $R L$ of materials from an environmental and social point of view. $R L$ policies and practice are viewed positively by the companies, which could inspire consumer confidence in an organisation that performs such activities and generate higher profits through new and continued consumer loyalty. Going green in relation to supply chain management based activities has proven to be important in molding companies' reputations as contributing in a corporate and socially responsible manner to the environment and society (Smith, 2012). Legislation refers to the laws and policies imposed by any jurisdiction which dictate the legal obligations of a company to take back returned products. The aforementioned three drivers are actually related to each other (Carter and Ellram, 1998). If the materials or end-products are returned to reduce waste for the environment, production costs can be reduced if the materials can be reused or remanufactured, and consumer satisfaction can be enhanced if the defective products are allowed to be returned (Marien, 1998).

Although the three drivers have been agreed by most researchers, Alvarez-Gil et al., (2007) argued that there is a need to find out why some companies implement RL more proactively than others; such organisations can be affected by the pressures from the external stakeholders (e.g., consumers, government, shareholders etc.), the availability of internal organisational resources, and the individual strategic stance of the decision makers (e.g. senior management) that includes operations strategy. 
Operational strategy directs and guides operational activity within a business. That said, the delivery of strategy and management is performed by staff who have their own personal drivers and experience. In the case of recycling engagement, performance can be influenced by organizational policies and procedures informed by strategy, but also by the personal principles and convictions held by staff. There is a case to be made for personal drivers sometimes overriding operational drivers. Recycling behavior in people has been an area of interest to marketing experts over the years, trying to understand the psyche of the customer and its relationship with recycling activities (Lansana, 1992). There is the view that those less engaged would be same group who would be interested in rewards for recycling efforts (Dahle and Neumayer, 2001). Knowing why people choose to recycle either from a corporate perspective (as a company or within a company) or directly as a customer and what drives that behaviour is similar to the RL drivers as proposed by de Brito et al (2004). Some researchers claimed that recycling consciousness is borne out of knowledge and education (Chen et al, 2012) whilst others believe involvement is based on criteria such as the activity being 'normalised' and convenient for customers to engage with (Vining and Ebreo, 1990). In a study undertaken by Chen et al (2012) examining recycling habits of inhabitants in small towns and large cities, city-dwellers tend to be better educated and suffer more pollution, so may be more aware of the issues involved.

For the purpose of this discussion the authors have adopted the definition of Reverse Logistics (RL) as meaning the as "the process of planning, implementing and controlling the efficient, cost-effective flow of raw materials, in process inventory, finished goods and related information from the point of consumption to the point of origin for the purpose of recapturing or creating value or for proper disposal" (Rogers and Tibben-Lembke, 1999, pp2). This refers to the management of stock returns internally in hospital pharmacy for recycling leading to re-use or final disposal/incineration.

Moving towards a sustainable medicines recycling system requires sound operational strategy and reasoning for what is done and why it is done. Developing a sustainable operations strategy requires an organization to define and apply clear operational logic to deliver corporate objectives, best practice and resources that support and enforce medicines $\mathrm{RL}$ and reduce waste production and circulation in hospital pharmacy in the NHS (UK).

\section{Methodology}

The purpose of this study is to examine medicines reverse logistics practice within the NHS hospital pharmacies, and the operational strategy which drives such practices. This work is qualitative and exploratory in that it seeks to know what strategy and practice is employed in this area of $R L$, how it is done and why this is the case. Qualitative research affords the researcher the ability to explore and probe into attitudes towards the studied phenomenon (Ghauri and Grønhaug, 2005) in a way that would not be obtained using purely quantitative data (Silverman, 2005). The case study method was adopted as it was considered appropriate in exploring an established topic in a new way to provide insights into whether behavior and process can combine to create greater effectiveness and enhanced service outcomes. A case study approach focuses on 'how' and 'why' rather than just the 'what?' (Smart et al. 2009:492). A purposive case study sample of five regional operational groups, named as Groups A, B, C, D and E, were chosen to participate in this study. Single case research provides depth of study whilst multiple cases augment external validity (Maxwell, 2002). The authors therefore chose to approach gatekeepers of a large number of hospital pharmacies for access to improve validity and generalisability of outputs.

The snowball technique was adopted in this study to select the participant sample (Eriksson and Kovalainen, 2008). Access was gained by approaching the Chairperson of Regional Operational groups who agreed access via $\mathrm{him} /$ herself to group members. The Chairpersons were senior pharmacy professionals such as Regional Procurement Pharmacists. The Chairperson then endorsed the survey completion to their group to increase the likelihood of participation. All but one of the groups were based in mainland England, Group E was not (but was still part of the UK). The data was collected between May 2011 and August 2012. These groups were chosen as it was convenient for the researcher (having a prior working/research relationship with some of the group members) and due to the fact that its members offered representation from a large number of NHS hospital pharmacies.

As each regional group had a varying number of members, to ensure a healthy response rate (in order to deliver generalisable and valid outputs) 5 regions were approached. Validity is concerned with the integrity of outcomes and credibility of the conclusions obtained in the study. Yin (2009) presents three widely used categories of validity: construct, internal and external. Reliability, or construct validity, relates to dependability or comparability (Schofield, 
2002) internal validity relates to the credibility of the work based on factual accuracy (Maxwell, 2002) and external validity (or generalisablity) is also referred to as translatability of transferability (Schofield, 2002). The methodology adopted in this study aimed to ensure that the agendas of all three elements were met, through the participant sample profile and size, data collection tool, analysis and approach. Triangulation of information from multiple cases within the UK was also considered to be a critical element to ensure a representative output was delivered, 45 participants providing answers to the same data set.

An electronic survey was developed which was circulated to group participants via the group chairperson. The survey consisted of 25 questions covering targeted areas of medicines recycling: description of current $R L$ system (resources used, technology, improvement plans), impetus for recycling, waste disposal, recycling guidance/directives and use of smart technologies. 45 responses were collected from 45 different sources. The number of respondents per group ranged from 15 to 3 .

The use of an electronic (e-) survey was felt most appropriate for this study and has become more commonplace in business (Gunn, 2002). The choice of which was based on convenience for both the respondent in completing it, the researcher in designing and disseminating it but also analysing the findings on an individual case basis but also to facilitate generalisability. The risks attached to this method were that respondents may have survey fatigue, but this was hopefully negated by the endorsement of the study via the Chairperson. The questions presented were a mix of structured (yes/no, likert-scale), and semi-structured, providing structure, guidance and openness in response.

The survey content was reviewed by Chairpersons from 2 out of the 5 regional groups to determine accuracy of content and interpretation. Both were perceived to be representative of the mainland UK (Group A) and non-mainland group (Group E). No alterations were sought from Group A and some adjustments were made to the Group E survey content; customisation was undertaken with the guidance of the Chairperson and was mainly altering of external body/association titles. This further supported the development of a representative and accurate survey tool. The survey was initially completed by Group A in April-May 2011. The respondents felt that the questions were appropriate and therefore the authors did not alter the survey content. This was then relaunched for Groups B, C and D in JuneAugust 2013 and a customized version released to Group E in January 2012. An overview of the data collection schedule is presented in Table I. Upon completion of the survey tool (Bristol Online Survey,

http://www.survey.bris.ac.uk) a web link was released to each Chairperson for dissemination to their group. The authors were not privy to the web link circulation list so therefore did not definitively know the number of potential contributors in all regions but were advised on occasions of the maximum number of contributors e.g. Group B stated that the maximum would be 15 and 13 responses were provided delivering an $87 \%$ response rate. Group $C$ also delivered 6 out of 11 responses (a $55 \%$ return rate).

Take in Table I

For the purposes of this analysis and to ensure confidentiality, all respondents have been anonymised and so are represented by alphabetical letters e.g. Respondent $A, B, C$ through to $A A, B B$ etc.

\section{Results}

Although NHS Pharmacies work to a common agenda i.e. delivering their services to patients, the manner in which they execute this can differ slightly between hospitals. In order to determine how medicines recycling was managed and performed, specific questions were targeted at understanding current practice and strategy. To this end participants were asked to complete an online survey which contained 25 questions. The questions were a mixture of closed (Yes/No), partially closed (offering a number of pre-determined answers)/likert-scale and open-ended questions (also including the Other category). The results were analysed and are presented as themes below. 


\section{Current recycling practice}

The initial question to all participants was to determine the presence of a medicines recycling system in their operation. 44 out of 45 respondents indicated that one was in place with $84 \%$ respondents stating that it had been in effect for 5 or more years. Only one respondent in the entire survey did not have a recycling system in place and this was due to this site having a pilot which was funded and was due to be reinstated in July 2012.

When defining 'medicines recycling' and offered a range of pre-determined definitions, the majority of participants stated that it was the practice of returning medicines stock from wards and other locations for re-use. Mild variations on this definition existed e.g. Respondent I stated the following: 'Return of stock from wards (not patients) for credit and redistribution and rotation of expiry date stock from wards - relocated to wards that will use it quicker to reduce the wastage'. Other respondents focused on the return of stock for re-use and final disposal so combining a number of RL elements. Respondent $L$ specifically commented on the return of packaging for recycling as opposed to the generic medicinal product.

As disposal of products is an important element of an $R L$ system, participants were asked how they managed medicines waste. The options provided to them in the survey were as follows: a) A third party waste management company comes to collect them; b) The destruction is conducted by our own staff who are authorised for the medicines waste treatment and c) Others. $82 \%$ (37) of participants said a third party waste management company comes to collect them and 2 of the remaining 8 said the destruction is conducted by their own staff who are authorised for the medicines waste treatment. Respondent $\mathrm{N}$ appeared to be less certain of the final disposal of returned products: "The waste is placed in waste bins and sent to a central location within the trust and, I assume collected by a third party", whereas Respondent $\mathrm{C}$ asserted that such products were incinerated in-house. Respondent $\mathrm{A}$ believed practice to be a mixture of a) and b) as controlled drugs are destroyed in-house and then collected for disposal. The general consensus was that this activity is best outsourced to a third party as it is not resourced internally.

\section{Strategy - why do it?}

In order to gain a better insight into the strategy supporting the practice of medicines recycling and the overarching $R L$ system, participants were asked why they recycled medicinal stock and from a predefined list asked to choose their top 5 reasons for doing so. The results are presented in the Table II below.

\section{Take in Table II}

All the listed criteria were ranked using a Likert scale 1 to $5 ; 1$ being the most popular and 5 the least popular. The reason which most underpinned recycling activity was I) to reduce waste. This was closely followed by II) saving money for the NHS and the hospital/Trust. Popular reasons following this were (in order of priority as determined by the total respondent group): III) be more efficient generally; IV) it's the right thing to do and because it is better for the environment. The least popular reason for conducting recycling activities was V) directives from Department of Health, which was surprising as this government body comprises a number of sub-groups, including the Commercial Medicines Unit who directly manage the pharmaceutical supply chain in the NHS. Not all respondents choose 5 reasons in their responses so the findings may not in this case present the full picture as represented by the respondent sample. All however did provided 3 plus reasons.

From a strategic perspective it was important to understand the systems employed to facilitate the management of medicines recycling. Participants therefore offered feedback on their systems which proactively reduced stock recycling and disposal. Only 4 participants out of 45 stated that they did not have a waste audit or stock management system in place to reduce stock becoming expired. There was a common factor in the respondents' answers which focused on the periodic review of stock lists and stock levels on wards and pharmacy stores. Other responses commented on stock management using higher level technology such as robots (Respondents A, M and O). "'[We] have a robot which picks by date stock is put into the robot. New stock gets a 12 month expiry unless a shorter expiry is used on input. Monitor stock using expiry date programme. Non robot areas checked every 3 months" (Respondent O). This was concurred by Respondent $Q Q$ who stated that [they produce a] monthly static stock report and monthly 
robot expiry report for stock currently held. [The hospital also has] strict management of entry of new drugs within the hospital"

The critical most frequently cited element was reviewing data proactively to avoid stock rotation and obsolescence e.g. "an audit was carried out at the end of 2010 and we are reviewing our policies. Also, we run expiries out of our automated dispensing system monthly" (Respondent $\mathrm{H}$ ) and "monthly expiry checking, stock moved between sites to ensure wastage minimal" (Respondent F). Some responses did seem to focus on less preventative and more reactive measures such as reviewing of all expired stock is investigated to avoid future reoccurrence.

Participants were also asked to share their views as to why medicines recycling are needed within their organisation and the NHS. The reduction of waste and saving money were common responses from this open-ended question. One respondent did state that it is too expensive to throw away all returns (Respondent $\mathrm{G}$ ), therefore the recycling activity, we can presume, is warranted. A different view was provided by Respondent $C$ who stated that an $R L$ system can help an organisation "see where we need to get our supplies right". This was the only response which focused on the broader supply chain perspective as opposed to the product or cost associated with it.

The role of external bodies and their influence on NHS pharmacy operations strategy and practice was explored in this section. There are a number of external associations who regulate or guide activity in the pharmaceutical supply chain, both in the NHS and in the pharmaceutical section e.g. manufacturers, wholesalers etc. Some include the Department of Health, Commercial Medicines Unit (within the DoH), Medicines and Healthcare products Regulatory Agency (MHRA), National Patient Safety Agency (NPSA). Participants were asked if guidance from external parties would improve medicines recycling, with $53 \%$ stating Yes and $47 \%$ saying No. A large majority of respondents (73\%) stated that all of the medicines recycling activity is developed and steered by internal staff as opposed to company or NHS guidance. Respondent $\mathrm{G}$ was the outlier in this question stating that operational practice complied with national guidance as opposed to company or NHS guidance.

All participants were asked to identify one directive/policy/piece of legislation which steers or governs medicines recycling. The results are presented in the Table III below.

Take in Table III

Of the 42 responses received, 26 of these stated that there were no directives or legislation which influenced recycling practices. Of this group, some were unsure if anything did exist. Others asserted that practice is steered by internal standard operating procedures and policies mainly to save money, aligned with NHS efficiencies and waste management policies/regulations. Respondents who answered this indicated their sources in order of use/preference: a) Regional groups; b) Regional pharmacy specialists; c) the Department of Health and the Commercial Medicines Unit (individual but jointly ranked); d) National groups; e) Pharmaceutical wholesalers; f) MHRA (Medicines and Healthcare products Regulatory Agency) and pharmaceutical manufacturers (individual but jointly ranked). There was one entire regional group (Group $\mathrm{C}$ ) who gave a negative response to this question, all stating that there was no influence from these parties. The most influential party were the regional groups of which the respondents all belonged to and who have a strong operational focus. What was surprising was the lack of influence (as determined by the findings) from the MHRA, who are the association who Governmental agency with responsibility for standards of safety, quality and performance and associated with medicines in the UK. An additional suggestion from Regional Group C was that support should be sought via benchmarking, "Other Trusts to benchmark effectiveness so that we could learn from them about potential improvements" (Respondent DD).

\section{Resource Utilisation}

From the findings it was evident that there was a disparity between resource utilisation in supporting the recycling of medicinal products. Grades in hospital pharmacy begin with health care support workers (previously known as Assistant Technical Officers or ATOs) (grades 1 through to 4), followed by Technicians (grades 5 to 7 ) and then onto senior managers (grade 7 plus). Alongside these groups there are qualified pharmacists beginning with pre- 
registration pharmacists (grade 5), first year registered pharmacists (grade 6) and higher grades 1 year plus qualification. The most popular grade identified from the 45 respondents undertaking recycling duties was Grade 2 health care support workers (ATOs). This appeared to be the grade deemed most appropriate to undertake this activity. However this was supported by mixed grades of staff ranging from the lowest Grade 1 up to senior members e.g. the Purchasing Manager through to all staff. Purchasing management responsibility can be undertaken by technician and qualified pharmacist staff in grades 7 and 8 (although there are different bands within this grading and regional pharmacy procurement specialists would be graded up to $8 \mathrm{D}$ ). Table IV presents a review of staff grades used in the recycling of medicinal products.

Take in Table IV

Participants were also asked how many staff were involved in this activity as opposed to the grade involved. $54 \%$ of respondents had 5 or more staff involved in this, 36\% used 2 to 5 staff and the remaining had only 1 to 2 staff members recycling returned medicines. This activity was well supported by nearly all hospitals as most respondents had a training package in place to ensure staff were well trained to undertake this. Such training included standard operating procedure and policies, mentoring and learning from experienced staff and variations on both of these. Where dedicated packages were not in place (in the minority) they were replaced by other appropriate qualifications/training mechanisms.

As technology performs a critical role in hospital pharmacy, with the functionalities for processing information of customers and products, and sustainability in technology and information systems is critical in the NHS (UK), participants were asked if the recycling activity in place was supported by technological applications. All the responses indicated that the main source of technology used to facilitate recycling was the pharmacy computer systems.

In answering this question the majority of the participants (64\%) stated that they would not be altering their current medicines recycling systems. Some respondents offered some comments as to why this was the case e.g. 'there is a very efficient system already in place' (Respondent G); "insufficient resources" (Respondent I); "the current system works efficiently within our resources" (Respondent K) and "didn't know that there may be a better way of dealing with this issue" (Respondent $\mathrm{N}$ ).

\section{Discussion}

Operations strategy over the years has been seen to adopt a new objective (aside from the standard quality, cost, speed etc.), this being sustainability. When considering the pharmaceutical supply chain as applied to hospital pharmacy and recycling of such products, there has to be a focus on sustainability of processes and systems to deliver best practice and sustainability of products and services. As stated previously, the three main drivers that motivate companies to adopt $\mathrm{RL}$ systems are identified as: economic, corporate citizenship, and legislation (de Brito et al., 2004). The results collated from this study indicate that all 3 drivers are prevalent in undertaking medicines recycling in hospital pharmacy and encouraging a more sustainable approach; to "...shape long term capabilities..." (Slack and Lewis, 3:2002) in RL competency through recycling strategy, resource utilisation, practice/policies employed and technology adoption.

Economic - From this point of view the evidence would suggest that the main reason for undertaking recycling within hospital pharmacy is to save money for the NHS and for hospitals. Not all stock returned to a pharmacy can be recycled for re-use (put back into stock) and will have to be disposed of effectively. Popular reasons as to why Trusts undertook medicines recycling were mainly to be more efficient generally, reduce waste, to save money for the NHS and to save money for us (hospital/Trust). Whilst the NHS is in a grip of efficiency realisation (PharmaTimes Online, 2011a), the cost and savings according to this survey were of equal importance to reducing waste and doing the right thing for the environment. This emphasises the striving for cost efficiency and reductions but not to the detriment of social and environmental consciousness (demonstrating the corporate citizenship driver). 
When reviewing the resources used in supporting this activity the most common staff grade involved was Grade 2. However, the range of grades was incredibly broad, from Grade 1 through to the Procurement Manager, Grade 7/8. This therefore indicates some possible disparity in the emphasis placed on this activity (if importance is to be judged by resource allocation) or it can mean that this activity can be handled in a more than capable manner by a lower banded grade. If this is the case, one may question the involvement of a procurement manager in medicines recycling. From an economic perspective, if such an activity can capably be performed by a lower banding then this will cost the NHS less and may be a better use of their resources. This data can be used effectively in determining best practice regarding recycling team composition, the quantity and grades of staff that should be utilized to deliver an effective output i.e. good recycling practice, accurate processing of stock for recovery and re-use.

According to Rogers and Tibben-Lembke (1999) RL involves the systematic planning and control of returning products to source. This can happen for a number of reasons, e.g. for returning to stock (hence creating value) or for final disposal (thus reducing risk due to use when out of date etc). The findings presented in this study indicate that medicines recycling, as part of the wider $\mathrm{RL}$ remit, involved returning stock from wards for re-use where possible. Disposal was also recognised as part of this activity and the majority of respondents said that this was handled by a third party externally. This was not considered as a core part of the RL system and therefore was outsourced or dealt with by waste management systems within the Trust but not the pharmacy staff. This again supports economic considerations in knowing who best to perform this activity and reduce additional staff costs.

All respondents seemed to have systems in place to proactively address reducing waste and therefore have less quantity of stock to be recycled. One respondent did stipulate that by performing such an exercise there can be a realisation of how well stock is being managed. Large quantities of returns can indicate over stocking, inflated stock needs, incorrect stock lists, inadequate stock review and rotation or faulty materials management systems or practice. Such an insight may make the case for further enhancements in technology etc to support the integration of enhanced environmentally focused activities/practice into operations strategy (Angell and Klassen, 1999). The main source of technology adopted to support medicines recycling was the standard pharmacy system with only a few respondents (3) stating that plans were underway to alter their recycling systems, but whether these were technological changes or not was not captured in this study. A recent study has indicated progression in the use of innovative technologies in healthcare arena including the use of social media (Pharmatimes Online, 2011b), however the findings of this study demonstrated that innovative technologies such as bar code scanning and smart phone applications were not commonly widespread in their use according to respondents but had the potential for great use if the infrastructure was in place. Such strategic improvements in recycling activities and supporting technologies should contribute to the QIPP agenda and NHS efficiency drive to save the £15-20 billion per year (Department of Health, 2010 and Department of Health, 2012).

Corporate citizenship - A large proportion of respondents in this survey stated that medicines recycling "is the right thing to do' and 'is better for the environment' indicating a high level of environmental and social consciousness. One could argue that in 'doing the right thing' and recycling the product, savings would be made anyway and the product would not be wasted or cause harm to the environment; this does not always directly apply to medicines as not all stock can be reused. One Group (Group E) stood out as an outlier in this study in the driver that they follow when recycling. There were only 3 responses from this group so the findings cannot be considered as representative for the whole region, but participants felt that recycling was performed due to policy, hazard reduction and environmental (green) consciousness, as opposed to savings or waste reduction. This supports the view as discussed in operational strategy, that in understanding drivers of recycling engagement, performance may be influenced more by personal principles and experience of staff (Chen et al., 2013; Alvarez-Gil et al., 2007) as opposed to strategy as deployed through policies and procedures. The activity of recycling does incur costs and at times there is no return on investment (a patient named medication must be destroyed and incineration costs have to be funded) so it may fall lower down the pecking order in how money and resources are deployed. Huge-Brodin and Anderson (2008) reiterate this, stipulating that engagement with this activity may only release economic value further downstream in the supply chain e.g. WEEE product recycling. This does not mean that there should not be a responsible, social and environmental consciousness associated with this activity, especially considering the potential economic benefits of 
effective recycling systems to reuse and reallocate stock which can be recycled. It is here that the corporate citizenship and economic drivers conflict and overlap.

Legislation - The results indicated that there does not appear to be dedicated directives or legislation which influences or governs medicines recycling in hospital pharmacy. Compliance with standard operating procedures (in-house) and regional quality control bodies, waste regulations etc were mentioned as sources of governance for this activity but the majority of respondents felt that there was no directives or they were not sure if they existed (had not heard of them). This is a concern as medicines recycling has been identified as a strong strand of activity in the NHS QIPP agenda and therefore requires strong leadership and consistency in approach (supported by correct guidance and steering from key documents/parties). It could be the case that as most of the recycling activity which appears to be organic and homegrown and is working effectively, then there is no impetus for provision to come from elsewhere? Alvarez-Gil et al., (2007) in reviewing why corporations adopt $R L$ practices asserted that there may be pressure from external parties, e.g. stakeholders, customers, shareholders etc but this is does not appear to be the case in this study. Any driving force fostering $R L$ practices such as medicines recycling is most definitely provided by NHS pharmacy staff and not influenced by external sources. This reinforces the ownership and control of the process as an internal consideration aligned with the corporate citizenship driver.

\section{Conclusions}

The purpose of this study is to examine medicines reverse logistics practice within the NHS hospital pharmacies, and the operational strategy which drives such practices. The concept of how, what and why (and why not) is explored in relation to medicines waste management and the strategy and practice supporting medicines recycling and waste reduction.

The latest guidance from the Department of Health (NHS UK) (2012) offers an action plan for medicines optimization and waste reduction. The actions proposed are deemed as best practice and the way forward to achieve said objectives. The outputs of this study indicate that at least 45 hospitals in the UK already have good practice in place in managing medicines recycling but the means by which this delivered and why in this manner varies between hospitals. In comparing these findings with the 2012 action place there is still room for improvement in adopting best practice such as regular waste audits, analysis of stock for fitness for re-use and return to stock and visibility/joined up knowledge in primary and secondary care dispensing (hospital and community). The findings and discussion of this study indicate that there is some commonality in the strategy employed in conducting medicines recycling in that NHS pharmacies feel that it is the right thing to do and it can lead to savings for both the Trust and the NHS and generally reduce waste. Current strategy and practice reflects the drivers for $\mathrm{RL}$ practice as derived by de Brito et al. (2004). These are all signs of an operations strategy which has an environmental consciousness and good practice.

The results clearly indicate that there is minimal influence and guidance for both strategy and guidance from NHS strategic bodies and regulatory agencies which is surprising. Rees (2011) commented on the 'disconnectedness' of the pharmaceutical industry and it may be that this lack of interaction between such bodies and NHS hospitals is an example of this or a victim of this? The drive to improve efficiencies and have robust medicines RL processes is firmly in the hands of the hospitals and not exterior to this. This output contradicts the work of Alvarez-Gil et al., (2007) as discussed previously.

The NHS (UK) is publicly accountable for all funds spent so best practice in procurement, materials management and disposal is critical to success. The means by which the NHS ensures they do this varies but relies on management and staff devising a sustainable operations strategy which encompasses sustainable thinking regarding the product, the service and the operation. The NHS is in an era where the term efficiency, QIPP etc. is a constant reminder of the pressure to perform in a manner which is appropriate and somewhat frugal but also where action has to be meaningful and has to have a focused purpose. Funds are needed to finance the NHS and funds in the PSC can be reabsorbed 
into the system by best practice such as the effective recycling of stock, identification of issues relating to stock management and acknowledgement of the cost of wasted stock and disposal. The latter entity is not always known but should be one of the drivers of medicines recycling and should influence operations strategy, practice and resource allocation for $\mathrm{RL}$ system development. This can be supported by regular waste audits where wasted medicines costs are calculated and departments informed of potential cost savings. The findings of this study demonstrate a high level of engagement in medicines recycling which provides a robust footing for sustainable systems and operational development for NHS Pharmacy in the UK.

Future research aims to pursue a broader multi-case analysis of recycling activity in hospital pharmacies on a global level. In doing so the authors hope to further explore the drivers for this activity as determined by de Brito et al. (2004) and impetus for recycling activity as purported by Alvarez-Gil et al. (2007). A mixed qualitative and quantitative approach will be adopted for future data collection and analysis.

\section{References}

Celesio Businesses. AAH Pharmaceutical Wholesaler. http://www.aah.co.uk/content/celesio-businesses-0 (Accessed: 17 January 2013).

Alvarez-Gil M.J., Berrone P., Husillos F.J., and Lado N. (2007), 'Reverse logistics, stakeholders' influence, organisational slack and managers' posture', Journal of Business Research, Vol.60, pp.463-473.

Andel T. (1997), 'Reverse logistics: a second chance to profit', Transportation and Distribution, Vol.38 No.7, pp.61.

Angell L.C. and Klassen R.D. (1999), 'Integrating environmental issues into the mainstream: an agenda for research in operations management', Journal of Operations Management, Vol.17, pp.575-598.

Breen L. (2005) Pharmaceutical Supply Chain Map, Bradford University Risk Workshop. Internal document.

Blumberg, D. F. (1999), 'Strategic examination of reverse logistics and repair service requirements, needs, market size, and opportunities', Journal of Business Logistics, Vol.20, pp.141-159.

Braund, R., Peake, B.M. and Shieffelbien, L. (2009), 'Disposal practices for unused medications in New Zealand', Environment International, Vol.35, pp.952-955

Carter, C.R. and Ellram, L.M. (1998) 'Reverse logistics: a review of the literature and framework for future investigation', Journal of Business Logistics, Vol.19 No.1, pp.85-102.

Chen, X., Nils Peterson, M., Hull, V., Lu,C., Hong, D., LiuHow, J (2012) 'Perceived Exposure to Environmental Harm Influences Environmental Behaviour in Urban China', Royal Swedish Academy of Sciences. Online. http://csis.msu.edu/sites/csis.msu.edu/files/www.springerlink.com_content_q5t161n15q882p38_fulltext.pdf (Accessed 26 January 2013).

Cherrett, T.J., Maynard, S., McLeod, F.N. and Hickford, A.J. (2012) 'Reverse logistics for the management of waste'. in McKinnon, A., et al. (Eds), Green Logistics: Improving the environmental sustainability of logistics, London, GB, Kogan, pp 242-262.

Coghlan, A. (2013) 'Time to halt our massive waste of food - here's how' New Scientist. http://www.newscientist.com/article/dn23067. (Accessed 13 January 2013).

Dahle, M. and Neumayer, E. (2001), 'Overcoming barriers to campus greening: a survey among higher educational institutions in London, UK', International Journal of Sustainability in Higher Education, Vol. 2 No. 2, pp. 139-59.

Daughton C.G. and Ternes T.A. (1999), 'Pharmaceuticals and personal care products in the environment: agents of subtle change?', Environmental Health Perspectives, Vol.107, pp.907-938. 
de Brito, M.P., Dekker, R., and Flapper, S.D.P. (2004), 'Reverse logistics: a review of case studies' In: Fleischmann M, Flapper S.D., (Ed.) Reverse logistics, quantitative models for closed-loop supply chains. Berlin: Springer; 2004. http://issuu.com/mrtn/docs/de-brito--m.p.--dekker--r.----flapper--s.d.p.- (Accessed 24 February 2013).

Department of Health (2010) The NHS quality, innovation, productivity and prevention challenge: an introduction for clinicians. Crown copyright.

http://www.dh.gov.uk/en/Publicationsandstatistics/Publications/PublicationsPolicyAndGuidance/DH_113809

(Accessed 14 January 2013).

Department of Health (2012) Improving the use of medicines for better outcomes and reduced waste. An Action Plan. Report and Action Plan of the Steering Group on Improving the Use of Medicines (for better outcomes and reduced waste). https://www.gov.uk/government/publications/action-plan-for-improving-the-use-of-medicines-and-reducingwaste. Accessed: 19th June 2013.

Department of Health (2013) A strategic framework to source pharmaceuticals for the NHS in England. Commercial Medicines Unit.. http://cmu.dh.gov.uk/home/ (Accessed 14 January 2013).

Eriksson, P. and Kovalainen, A. (2008) Qualitative Methods in Business Research. London: Sage Publications.

Ghauri, P. and Grønhaug, K., (2005) 'Research Methods in Business Studies' $3^{\text {rd }}$ Ed. Harlow, Essex: Prentice Hall

Gonzalez-Torre, P.L., Adenso-Diaz, B. and Artiba, H. (2004), 'Environmental and reverse logistics policies in European bottling and packaging firms', International Journal of Production Economics, Vol. 88 No.1, pp. 95-104.

Gonzalez-Torre, P.L. and Adenso-Díaz, B. (2006), 'Reverse logistics practices in the glass sector in Spain and Belgium', International Business Review, Vol. 15No.5, pp.527-546.

Gunn, H. (2002), 'Web based surveys: changing the survey process' First Monday, 7 (12) Online http://firstmonday.org/htbin/cgiwrap/bin/ojs/index.php/fm/article/view/1014/935 (Accessed 24 February 2013).

Gupta, M. (1995), 'Environmental management and its impact on the operations function', International Journal of Operations and Production Management, Vol. 15 No. 8, pp. 34-51.

Gupta, M., Sharma, K. (1996), 'Environmental operations management: an opportunity for improvement', Production and Inventory Management Journal, Vol.37 No.3, pp.40-46.

Hassan, M.M., Ahmed, S.A., Rahman, K.A. and Biswas, T.K. (2008), 'Pattern of Medical Waste Management: Existing Scenario in Dhaka City, Bangladesh', BMC Public Health, Vol. 8, pp. 36.

Huge-Brodin, M., Anderson, H. (2008),'Recycling calls for revaluation', Supply Chain Management: An International Journal, Vol. 13 No 1 pp. $9-15$.

Jang,Y.C., Lee, C.. Yoon, O.S. and Kim, H., (2006) 'Medical Waste Management in Korea', Journal of Environmental Management, Vol. 80, No. 2, pp. 107-115.

Kleiner, A. (1991), 'What does it mean to be green?', Harvard Business Review, July-August 1991, pp. 38-47.

Lansana, F. (1992), 'Distinguishsing potential recyclers from non recyclers: a basis for developing recycling strategies', The Journal of Environmental Education, Vol. 23, pp. 16-23.

Lau, K.W. and Wang, Y. (2009), 'Reverse logistics in the electronic industry of China: a case study', Supply Chain Management: An International Journal, Vol.14 No.6, pp. 447-465.

Lebreton, B. and Tuma, A. (2006), 'A quantitative approach to assessing the profitability of car and truck tire remanufacturing', International Journal of Production Economics, Vol. 104 No.2, pp. 639-652.

Lovino, Z. (2011) 'Garbage-sorting robot gets its hands dirty'. NewScientist.

http://www.newscientist.com/article/mg21028065.000-garbagesorting-robot-gets-its-hands-dirty.html (Accessed 13 January 2013).

Mackridge, A. J. and Marriott, J. F. (2007). 'Returned medicines: waste or a wasted opportunity?' Journal of Public Health, Vol. 29No.3, pp.258-62.Marien, E. J. (1998), 'Reverse logistics as competitive strategy', Supply Chain Management Review, Vol.34 No.2, pp.43-52. 
Marshall, M. (2011) 'Essential green metals are being thrown away'. New Scientist.. http://www.newscientist.com/article/dn20523 (Accessed 12 January 2013).

McDonough, W. and Braungart, M. (2002) 'Cradle to Cradle: Remaking the Way We Make Things', Farrar, Straus and Giroux, New York, as cited in Webster, K. and Johnson. C. (2010) Sense and Sustainability. Educating for a Circular Economy. The Ellen McArthur Foundation. https://emf.s3.amazonaws.com/S\%26S_2010C.pdf (Accessed 13 January 2013).

Mc Kenna, P. (2012) 'Fracking could be combined with carbon capture plans'. New Scientist. http://www.newscientist.com/article/dn22232-fracking-could-be-combined-with-carbon-capture-plans. html (Accessed 14 January2013.)

Pati, R.K., Vrat, P. and Kumar, P. (2008), 'A goal programming model for paper recycling system', OMEGA: International Journal of Management Science, Vol. 36 No.3, pp. 405-417.

Qdais, H.A., Rabi, A, and Abdulla, F. (2007) Characteristics of the medical waste generated at the Jordanian hospitals, Clean Techn Environ Policy, Vol. 9, pp. 147-152

Pharmatimes (2011) GPs facing new ban on high-cost drugs.

http://www.pharmatimes.com/Article/11-04-14/GPs_facing_new_bans_on_high-cost_drugs_report_claims.aspx Article a (Accessed 7 June 2011).

Pharmatimes (2011) Social Networks: rich pastures for drug use.

http://www.pharmatimes.com/Magazine/Social-networks-rich-pastures-for-drug-research.aspx Article b (Accessed 7 June 2011).

Rees, H. (2011) Supply Chain Management in the Drug Industry. Delivering patient value for pharmaceuticals and biologics. John Wiley \& Sons Inc Publishing. New Jersey.

Ritchie, L., Burnes, B., Whittle, P. and Hey, R. (2000), 'The benefits of reverse logistics: the case of the Manchester Royal Infirmary Pharmacy', Supply Chain Management: An International Journal, Vol. 5 No. 5, pp. 226-233.

Rogers, D.S. and Tibben-Lembke, R.S. (1999), 'Going Backwards: Reverse Logistics Trends and Practices', Reverse Logistics Executive Council Press, Pittsburgh, PA.

Schofield, J., Ward (2002) Increasing the Generalisability of Qualitative Research. In: Huberman, A. M. and Miles, M. B. (Eds.) The Qualitative Researcher's Companion. Thousand Oaks; London: Sage, pp. 171-204.

Shareefdeen, Z, M. (2012) Medical Waste Management and Control, Journal of Environmental Protection, Vol. 3, No.12, pp. 1265-1268.

Shih, L.H. (2001), 'Reverse logistics system planning for recycling electrical appliances and computers in Taiwan', Resources, Conservation and Recycling, Vol. 32 No.1, pp. 55-72.

Silverman, D (2005) "Doing Qualitative Research: A practical handbook" 2nd Ed. London: Sage Publications.Slack, N., Chambers, S. and Johnston, R. (2010), Operations management, Sixth Edition, Pearson Education Limited, Essex, England.

Slack, N. and Lewis, M. (2002), Operations Strategy, First Edition, Pearson Education Limited, Essex, England.

Smart, P., Maddern, H. and Maull, R. (2009) Understanding Business Process Management: Implications for Theory and Practice. British Journal of Management, 20 (4), pp. 491-507.Smith, A.D. (2012) Gender Perceptions of Management to Green Supplier Development, International Journal of Procurement Management, Vol. 5, No. 1, 2012, pp. 55-86.

South, S. (1998), 'Managing returned freight', Inbound Logistics, Vol. 18 No. 12, pp. 48.

van Hoek, R. I. (1999), 'From reversed logistics to green supply chains', Supply Chain Management, An International Journal, Vol. 4 No.3, pp. 129-135.

Vining, J. and Ebreo, A. (1990), 'What's makes a recycler? A comparison of recyclers and non Recyclers', Environment and Behavior, Vol. 22 No. 1, pp. 55-73.

Xie, Y. and Breen, L., (2012) 'Greening community pharmaceutical supply chain in UK: a cross boundary approach.', Supply Chain Management: An International Journal, Vol 17 No1 pp 40-53. 
Zhou, L., Naim, M.M. and Wang, Y. (2007), 'Soft systems analysis of reverse logistics battery recycling in China', International Journal of Logistics: Research and Applications, Vol.10, No.1, pp. 57-70.

Yin, R. K. (2009) Case Study Research. Design and Methods. (Applied Social Research Methods Series) Vol. 5. London: Sage Publications.

Table I Data collection schedule for medicines recycling survey

\begin{tabular}{|c|c|c|c|}
\hline Time & Activity & Output & $\begin{array}{l}\text { Response } \\
\text { achieved }\end{array}$ \\
\hline $\begin{array}{l}\text { March } \\
2011\end{array}$ & $\begin{array}{l}\text { Consultation with Chairperson of } \\
\text { Group A regarding survey } \\
\text { content }\end{array}$ & $\begin{array}{l}\text { Content deemed appropriate } \\
\text { and survey launched }\end{array}$ & \\
\hline $\begin{array}{l}\text { April } \\
2011\end{array}$ & Survey launched for Group A & $\begin{array}{l}\text { Survey completed with no } \\
\text { interpretation issues or } \\
\text { requests for alterations }\end{array}$ & 15 \\
\hline $\begin{array}{l}\text { January } \\
2012\end{array}$ & $\begin{array}{l}\text { Consultation with Chairperson of } \\
\text { Group E regarding survey } \\
\text { content }\end{array}$ & $\begin{array}{l}\text { Minor customisation of } \\
\text { association/body names to } \\
\text { reflect different NHS } \\
\text { structure. }\end{array}$ & \\
\hline $\begin{array}{l}\text { January } \\
2012\end{array}$ & Survey launched for Group E & $\begin{array}{l}\text { Survey complete. Small } \\
\text { cohort circulation (Number } \\
\text { unknown). }\end{array}$ & 4 \\
\hline \multirow[t]{2}{*}{$\begin{array}{l}\text { June } \\
2012\end{array}$} & $\begin{array}{l}\text { Survey launched for Groups B, } \\
C \text { and D }\end{array}$ & $\begin{array}{l}\text { Survey completed by all } \\
\text { groups }\end{array}$ & 27 \\
\hline & & Total & 45 \\
\hline
\end{tabular}

Table II Analysis of strategic impetus driving recycling activities in NHS hospital pharmacy.

\begin{tabular}{|l|c|c|}
\hline Impetus behind recycling activity & $\begin{array}{c}\text { Number of } \\
\text { affirmations } \\
\text { from all } \\
\text { respondents }\end{array}$ & $\begin{array}{c}\% \text { of responses out of } \\
\text { total }\end{array}$ \\
\hline Reduce waste & 42 & 93 \\
\hline To save money for the NHS & 40 & 89 \\
\hline
\end{tabular}




\begin{tabular}{|l|c|c|}
\hline To save money for us (hospital/Trust) & 38 & 84 \\
\hline Be more efficient generally & 33 & 51 \\
\hline It's the right thing to do & 23 & 38 \\
\hline Because it is better for the environment & 17 & 20 \\
\hline $\begin{array}{l}\text { Because there is a policy in place within } \\
\text { the organisation to do so }\end{array}$ & 9 & 18 \\
\hline It reduces potential hazards & 8 & 4 \\
\hline Other & 2 & 0 \\
\hline Directives from Department of Health & 0 & \\
\hline
\end{tabular}

Table III Impact of directives/legislation on steering medicines recycling systems and practice.

\begin{tabular}{|c|l|}
\hline \multicolumn{1}{|c|}{$\begin{array}{c}\text { Number of } \\
\text { responses }\end{array}$} & Nature of response \\
\hline 20 & None \\
\hline 6 & Not sure and would need to check \\
\hline 3 & Internal procedure \\
\hline 1 & Department of the Environment \\
\hline 4 & $\begin{array}{l}\text { Recycling Medicines Policy } \\
\text { Waste management regulations/policy and guidance from external } \\
\text { party }\end{array}$ \\
\hline 5 & $\begin{array}{l}\text { Request of the Chief Pharmacist/policy approved by Chief } \\
\text { Pharmacist, }\end{array}$ \\
\hline 2 &
\end{tabular}

Table IV Review of staff grades (based on banding/grading) used in the recycling of medicines products.

\begin{tabular}{|l|c|c|c|c|c|c|}
\hline & \multicolumn{6}{|c|}{ Positive responses (quantity) } \\
\hline Grade & A & B & C & D & E & Total \\
\hline 1 & 1 & NA & NA & NA & NA & 1 \\
\hline 2 & 12 & 2 & 4 & 5 & NA & 23 \\
\hline
\end{tabular}




\begin{tabular}{|l|c|c|c|c|c|c|}
\hline 3 & 6 & 2 & 1 & 2 & NA & 11 \\
\hline 4 & 6 & 2 & 1 & 1 & 1 & 11 \\
\hline 5 & 4 & 1 & 1 & 1 & NA & 7 \\
\hline 6 & 3 & NA & NA & NA & NA & 3 \\
\hline 7 & 1 & NA & NA & NA & NA & 1 \\
\hline 8 & 1 & NA & NA & NA & NA & 1 \\
\hline $\begin{array}{l}\text { ATOs/ Technicians/ } \\
\text { Pharmacists (and /or) }\end{array}$ & 1 & 1 & 1 & 2 & NA & 5 \\
\hline Senior Assistant & NA & NA & NA & 1 & NA & 1 \\
\hline Purchasing manager & 1 & NA & NA & NA & NA & 1 \\
\hline $\begin{array}{l}\text { Mixed grades of } \\
\text { technicians }\end{array}$ & NA & 3 & 2 & 1 & 1 & 7 \\
\hline $\begin{array}{l}\text { Health Care Support } \\
\text { workers }\end{array}$ & NA & 0 & 0 & 0 & 1 & 1 \\
\hline All staff & 1 & 0 & 1 & 1 & 4 \\
\hline
\end{tabular}

Not Applicable (NA) indicates that no staff member of this grade is responsible for recycling activities. 


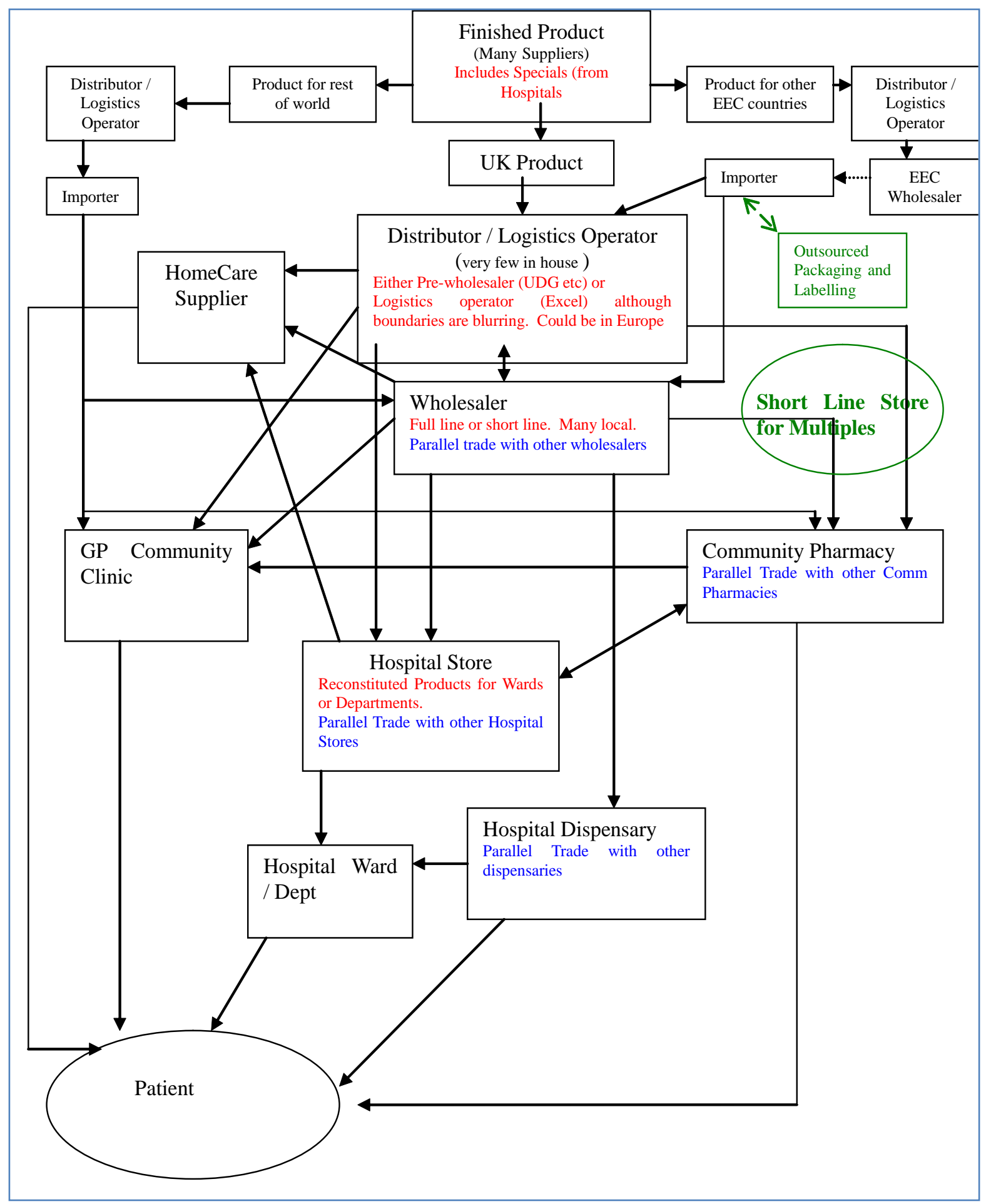

Figure 1. Pharmaceutical Supply Chain Map (Bradford University Risk Workshop, Breen 2005).

Keywords: Pharmaceutical supply chain, reverse logistics, recycling, operational strategy, medicines waste analysis/processing. 